\title{
The effect of new environment on adapted genetic architecture
}

\author{
Graham J. Holloway, \\ Susan R. Povey and \\ Richard M. Sibly
}

Department of Pure and Applied Zoology,
School of Animal and Microbial Sciences,
University of Reading, Whiteknights, P.O. Box 228,
Reading, Berkshire RG6 2AJ, U.K.

Central to the study of life cycle evolution is the concept of genetic trade-offs. Genetic trade-offs between life cycle characters develop as a result of the accumulation of genes with antagonistic pleiotropic effects. In the present study a comparison was made between the genetic architecture that had evolved in the ancestral environment and the way that this genetic architecture was disrupted following transfer to a new environment. It was predicted that, in the ancestral environment, genetic trade-offs should have evolved between each life cycle character and, as a result of these genetic trade-offs, significant levels of additive genetic variation should remain despite many generations of selection.

Following transfer to a new environment different genes might be expressed. Therefore, it was predicted that in the new environment the levels of additive genetic variation should increase and that the genetic trade-offs should break down. The predictions were well supported by the data.

\section{INTRODUCTION}

Natural selection acting on the available range of phenotypes in a population will favour genes with the highest fitness (i.e., the highest per capita rate of increase), resulting in adaptation. Phenotypes are the consequence of the expression of a multitude of genes and adaptation occurs through numerous direct and correlated responses to selection. Some genes have pleiotropic effects (Rose, 1982) so that they affect the values of more than one character simultaneously and produce genetic correlations between characters (Williams, 1966; Rose and Charlesworth, 1981a, b; Møller et al., 1989). Genetic correlations between primary fitness characters such as fecundity, development period and mortality rate (Sibly and Calow, 1986), can profoundly affect the rate and course of evolution. A positive genetic correlation may cause two characters, both of which are positively (or negatively) correlated with fitness, to respond more rapidly to natural selection than an independent character (Falconer, 1981) and genes with positive effects on covariance will ultimately be driven to fixation. Any genetic covariance remaining

\footnotetext{
* Present address: Section of Evolutionary Biology, Department of Population Biology, University of Leiden, Schelpenkade 14a, 2313 ZT Leiden, The Netherlands.
}

between two such characters at selective equilibrium will be negative, so that a favoured response in one character will be associated with a disfavoured response in the second character. Negative genetic covariance between two fitness characters influences energy partitioning processes at the physiological level. Hence genetic correlations or genetic trade-offs between fitness characters are central to the evolution of life-cycles.

Investigating experimentally the genetic relationships that evolve during adaptation has proved difficult, mainly due to the lack of control over the environment in which evolution took place. In the present study, we utilised laboratory populations of the rice weevil, Sitophilus oryzae. $S$. oryzae is a cosmopolitan pest of raw stored cereal grains (Champ and Dyte, 1976) and infests bulks of grain ranging from small quantities in pantries to huge silos. Therefore, its "natural" environment is readily reproducible in the laboratory. One of the populations used in the present study had been maintained on wheat for over 50 generations under constant conditions at the time of the experiment. It is likely that such a length of time in a constant environment is sufficient for selection to produce the genetic architecture described above. So in this wheat breeding population we predicted that: 
1. Genetic correlations reflecting genetic trade-offs should have evolved between primary fitness characters due to negative pleiotrophic gene action and

2. a significant amount of additive genetic variation should exist for each of these characters because of this negative pleiotropy, even though the characters had been subjected to natural selection for a long period of time.

Despite the logic behind the evolution of genetic trade-offs, rather few experimental studies have produced results consistent with their existence. Notable successful studies include Rose and Charlesworth (1981a,b), Soliman (1982), Luckinbill et al. (1984) and Møller et al. (1989). However, more frequently studies have failed to show genetic trade-offs (e.g., Giesel and Zettler, 1980; Giesel et al., 1982; Murphy et al., 1983; Stearns, 1983; Bell 1984a, $b$, also see review Bell and Koufopanou, 1986). Most of these studies can be criticized in that either small or laboratory inbred populations were used, or the experiments were carried out in a novel environment. Inbreeding is known to reduce net fitness (Mackay, 1985) and Rose (1984) pointed out that inbreeding may produce a number of inferior genotypes which could result in a spurious genetic correlation. Gene expression is environment dependent (Strickberger, 1968; Goodenough, 1978) and placing a population into a novel environment could cause the expression of many new genes. Since natural selection will not have acted on these genes, a selected genetic correlation could break down both through increased genetic variation and the operation of genes with positive pleiotropic effects (Service and Rose, 1985; Bell and Koufopanou, 1986). In order to examine the effect of a novel environment on adapted genetic relationships between fitness characters, a large number of $S$. oryzae were transferred from wheat to yellow splitpea. Yellow split-pea, as with all Leguminosae, contains a variety of toxic secondary compounds (Harborne et al., 1971). When forced to feed on legumes, many $S$. oryzae succumb due to the effects of these compounds (Holloway, 1986a). Thus to ensure the maintenance of genetic variation a large number of wheat breeding $S$. oryzae were transferred to yellow split-pea, knowing that a proportion of the animals were not going to survive to breed. As a result of this transfer it was predicted that, due to novel gene expression:

3. additive genetic variance in each primary fitness character will increase relative to pre-transfer levels and
4. the genetic trade-offs between these characters will break down and the genetic correlations will move away from their adapted values because of novel positive pleiotropy.

MATERIALS AND METHODS

\section{The insects}

The experimental $S$. oryzae originated from Tanzania and since 1979 have been cultured in the laboratory at Reading, England, on wheat. $S$. oryzae is an ideal animal to use for this type of study since its natural environment (from small to very large bulks of stored grain) is readily reproducible in the laboratory. To start a new culture about 400 adult insects of mixed ages were taken at random from an old culture and placed onto fresh wheat (Triticum aestivum) or yellow split-pea (Pisum sativum). The number of insects transferred ensured the maintenance of as much genetic variation as possible. We estimate that less than 20 per cent of the genetic variation present in the original population had been lost through genetic drift at the time of the current study. New cultures were set up every eight weeks and since $S$. oryzae takes about five weeks to complete its life cycle (egg to emergent adult) under laboratory conditions, only offspring from the first generation (plus a few old adults) were transferred to a new culture. In the present study a culture cycle is referred to as a generation.

The insects had been reared for over 50 generations on wheat at Reading and since the life history of $S$. oryzae is influenced markedly by temperature and relative humidity (Evans, 1982), the cultures and experiments were kept in a constant environment $\left(30^{\circ} \mathrm{C}\right.$ and 70 per cent relative humidity, CTH conditions). A large sample of wheat breeding insects was taken at random and transferred to yellow split-pea to initiate a new breeding population. These populations will henceforth be referred to as the W and W-P populations, respectively. The $\mathrm{W}-\mathrm{P}$ population was allowed to establish itself for five generations prior to the experiment.

Prior to use, all experimental food was frozen at $-20^{\circ} \mathrm{C}$ for one week. S. oryzae is very susceptible to grain moisture content (Evans, 1982; Holloway, 1985), so grain moisture content was equilibrated to $\mathrm{CTH}$ conditions prior to use (Richards, 1947). 


\section{Experimental design}

A nested half-sib full-sib mating design was used. In view of the large standard errors frequently associated with estimates of genetic correlations, we aimed to set up at least 50 half-sib families with 20 values in each family, making a total of 1000 values.

Cultures from which experimental insects were to be collected were first cleared of all adult insects by sieving. The cultures were then left for one day before being sieved again to separate any newly emerged adult weevils from the grain. $S$. oryzae females will not mate during the first day after emergence from the grain (Singh \& Soderstrom, 1963), thus the insects were virgin when collected. Expecting to lose some families as the experiment progressed, $65 \mathrm{~W}$ males and $69 \mathrm{~W}-\mathrm{P}$ males were each provided with five females from their respective populations. The males and females were left together for one week after which time the males were removed and discarded. The females were then placed individually into $50 \times 25 \mathrm{~mm}$ glass tubes each capped with a perforated plastic top. The $\mathrm{W}$ females were each provided with $5 \mathrm{~g}$ of wheat, while the W-P females were placed on $5 \mathrm{~g}$ of yellow split-pea. The female weevils were allowed to oviposit for three weeks before being discarded. Emergence of the F1 began on the 28th day from the beginning of oviposition. Newly emerged F1 were removed from the tubes on the day of emergence, separated by sex to retain virginity and placed on fresh wheat. A female's oviposition rate will be influenced by her father's genes rather than her mate's genes. In order to estimate the effect of each parental male's genes on fecundity, the experiment was taken through to a second generation. After seven days of emergence, sib: sib pairings were set up, four per parental female, so that 20 pairings were derived from each parental male, if possible. Each pair was placed into a clean $50 \times 25 \mathrm{~mm}$ glass tube containing six grains of wheat (for $\mathrm{W}$ females) or three yellow split-pea (for W-P females). The insects were allowed to mate and oviposit for five days before being discarded. Oviposition was restricted to a relatively short period of time to improve the precision of development period estimates.

$S$. oryzae lays eggs inside cereal grains and legumes. The excavated cavities, into which each egg is laid separately, are sealed with gelatinous plugs. The presence of an egg plug at the surface of a grain unambiguously indicates the presence of an egg beneath (Shazali, 1982). The wheat grains and yellow split-peas were examined individually under a Wild binocular microscope at $\times 25$ magnification for the presence of egg plugs. These fecundity estimates had to be complete prior to emergence of the F2 and the consequent destruction of a proportion of the egg plugs.

On the 27 th day from the beginning of oviposition and thereafter the tubes were inspected for the emergence of $F_{2}$ insects. The development period $\left(t_{j}\right)$ and body weight (bwt) to the nearest $1 \mu \mathrm{g}$ (measured on a Cahn 29 Automatic Electrobalance) of each emerging female insect was recorded. After 50 days from the start of oviposition the experiment was terminated. Estimates of survival $\left(S_{j}\right)$ were made by dividing the number of F2 emerging by the number of eggs laid. The instantaneous per capita mortality rate $\left(\mu_{j}\right)$ was estimated using the formula $\mu_{j}=-\left(\log _{\mathrm{e}} S_{j}\right) / t_{j}$ (Povey et al, in preparation).

\section{Statistical analysis}

\section{Analysis of variance}

The data were derived from a nested half-sib fullsib experimental design. Unbiased estimation of genetic variances and covariances relies on a number of assumptions, such as the avoidance of the mating of closely related individuals. This was not the case in the present study. However, outcrossing females from each sire group with unrelated individuals would have produced a mean degree of relatedness between the parental male and the $\mathrm{F} 2$ of $1 / 4$. This would have reduced the precision of the final estimates since smaller samples of the parental males genome would have remained for examination. Sib mating will sometimes result in the pairing up of deleterious recessive alleles, so that some families may perform badly (Rose, 1984). To alleviate this source of bias, sire groups containing less than five values were omitted from the analysis as their inclusion would have accentuated the overall variation between sire groups. We assumed that sire groups producing higher numbers of offspring were not suffering from any deleterious effects of homozygosity.

The data were analysed using the nested procedure in SAS. The causal components of variation were estimated from the mean square values in the anova table. The relationship between additive genetic variance $\left(V_{a}\right)$ and the variance between half-sib families $\left(V_{s}\right)$ is described by Falconer (1981 chapter 10):

$$
V_{s}=1 / 4 V_{a}
$$

and heritability $\left(h^{2}\right)$ is:

$$
h^{2}=V_{a} / V_{p}
$$


where $V_{p}$ is the total phenotypic variance. The additive genetic correlations $\left(r_{a}\right)$ were calculated using the expression:

$$
r_{a}=\operatorname{cov}_{a(\mathrm{xy})} / \sqrt{\left(V_{a(\mathrm{x})}\right)\left(V_{a(\mathrm{y})}\right)}
$$

where $\operatorname{cov}_{a(x y)}$ is the additive genetic covariance between the two characters X and Y (Becker, 1967; Falconer, 1981).

Accurately estimating the standard errors of $V_{a}$ and $r_{a}$ is, at present, not possible using unbalanced data sets from nested designs (Sokal \& Rolhf, 1981) in conjunction with the conventional procedures described by, for example, Becker (1967). As Searle (1971) pointed out, sampling variance estimates from unbalanced designs are likely to be biased to an unknown extent and direction. It is possible to overcome this problem though by using non-parametric resampling techniques, providing sufficiently powerful computing facilities are available (Diaconis and Efron, 1983). The Jackknife (Arvesen and Schmitz, 1970; Miller, 1974) was used here to generate estimates of $V_{a}$, $r_{a}$ and the associated standard errors. Jackknifing reduces bias substantially without the need for the data set to be balanced. The estimates produced are accurate if the data are normally distributed, but remain robust under conditions of nonnormality. However, this is only true if appropriate variance stabilizing transformations are made beforehand. For Jackknifing variance, $\log _{\mathrm{e}}$ transformation is generally recommended (Arvesen and Schmitz, 1970; Miller, 1974). However, since $\log _{e}$ of zero equals minus infinity, obtaining a confidence interval overlapping with zero on backtransformation is not possible. Therefore, $V_{a}$ was cube root transformed as a suitable alternative to $\log _{e}$, but with the added advantage of allowing confidence intervals to overlap with zero ( R. H. Smith, personal communication; Krzanowski, 1988). The genetic correlations were $z\left(\tanh ^{-1}\right)$ transformed (Arvesen and Schmitz, 1970; Miller, 1974).

\section{RESULTS}

The novel set of selective forces in the yellow split-pea environment did have an overall effect on the genetic architecture of the W-P population relative to the $\mathrm{W}$ population, as predicted (see introduction). This was established by comparing genetic variance/covariance matrices (Krzanowski, 1988). Subtraction of the weighted determinants from the joint matrix determinant produced a $-2 \log _{\mathrm{e}} \lambda$ value of 130 . Since $-2 \log _{\mathrm{e}} \lambda$ is asymptotically distributed as chi-squared, with 10 degrees of freedom the $\mathrm{W}$ and $\mathrm{W}-\mathrm{P}$ matrices were significantly different $(P<0.001)$.

Table 1 shows the mean values of the fitness characters measured in the $\mathrm{W}$ and $\mathrm{W}-\mathrm{P}$ populations in their respective environments (wheat and yellow split-pea). Where possible, the study focussed on female values. Adult body weight (bwt) increased following transfer to yellow splitpea, as did juvenile development period $\left(t_{j}\right)$. However, daily oviposition rate $(N)$ and juvenile mortality rate $\mu_{j}$ both declined in the new environment (yellow split-pea). All of the differences between the corresponding pairs of values in the $\mathrm{W}$ and $\mathrm{W}-\mathrm{P}$ strains were statistically significant $(P<0.001)$.

Table 2 shows the estimates of $V_{a}$ for the fitness characters measured in the two populations. In agreement with prediction 2 (see introduction) each character had a level of $V_{a}$ significantly greater than zero to at least $P<0.05$ in the ancestral wheat environment. This was also true of the novel (yellow split-pea) environment. In accordance with prediction $3, V_{a}$ for $t_{j}$ and $\mu_{j}$ increased following transfer to yellow split-pea, but only $V_{a}$ for $t_{j}$ increased significantly $(t=2 \cdot 897, P<0.01)$. $V_{a}$ for $N$ declined marginally in the new environment, but not to a statistically significant extent. Body weight also declined in the new environment, though not significantly, but no prediction had been made concerning this character.

The characters influencing fitness directly in table 3 are $t_{j}, \mu_{j}$ and $N$ (Sibly and Calow, 1986; Sibly, 1989). $t_{j}$ and $\mu_{j}$ both scale negatively with fitness, whilst $N$ scales positively with fitness. With this in mind, the signs of all three $r_{a}$ between these characters in table 3 are consistent with the existence of genetic trade-offs in the ancestral (W) environment (prediction 1). However, only one of the $r_{a}$ values ( $\mu_{j}$ versus $N$ ) is significantly different from zero. Untransformed data was jackknifed to attach intervals to the latter $r_{a}$ due to the number of $r_{a}$ estimates exceeding $1 \cdot 0$. None of the $r_{a}$ with bwt are significantly different from zero.

After five generations of selection in the novel environment (yellow split-pea), two of the three $r_{a}$ values involving only the primary fitness characters changed substantially (first two columns of table 3 ), although none of the changes were statistically significant. $r_{a}$ between $t_{j}$ and $\mu_{j}$ increased by 0.55 and $r_{a}$ between $\mu_{j}$ and $N$ decreased by 0.53 . Both of these changes are in agreement with prediction 4. $r_{a}$ between bwt and $N$ increased by 0.58 . The other $r_{a}$ retained similar values when transferred to the new environment. 
Table 1 Mean values of various fitness characters ( \pm standard error) for the $\mathrm{W}$ and $\mathrm{W}-\mathrm{P}$ populations of $S$. oryzae. The sample sizes from which the means are estimated are in parentheses

\begin{tabular}{lll}
\hline Character & W population & W-P population \\
\hline Female development period (days) & $33.04 \pm 0.07$ & $40.52 \pm 0.09$ \\
& $(2290)$ & $(1621)$ \\
Instantaneous mortality rate & $0.037 \pm 0.42 \times 10^{-3}$ & $0.026 \pm 0.47 \times 10^{-3}$ \\
Oviposition rate/female/day & $(823)$ & $(778)$ \\
& $3.61 \pm 0.042$ & $2.12 \pm 0.033$ \\
Female body weight $(\mathrm{mg})$ & $(823)$ & $(778)$ \\
& $1.73 \pm 4.5 \times 10^{-3}$ & $1.87 \pm 6 \times 10^{-3}$ \\
& $(2286)$ & $(1621)$ \\
\hline
\end{tabular}

Table 2 Estimated additive genetic variances in fitness characters for the W and W-P populations of $S$. oryzae. 95 per cent confidence intervals are in parentheses

\begin{tabular}{lll}
\hline Character & W population & W-P population \\
\hline Female development period (days) & $1 \cdot 15$ & $8 \cdot 17$ \\
& $(0 \cdot 20: 3 \cdot 47)$ & $(3 \cdot 61: 15 \cdot 51)$ \\
Instantaneous mortality rate & $2 \cdot 1 \times 10^{-5}$ & $5 \cdot 4 \times 10^{-5}$ \\
& $\left(4 \cdot 3 \times 10^{-6}: 5 \cdot 8 \times 10^{-5}\right)$ & $\left(2 \cdot 3 \times 10^{-5}: 1 \cdot 0 \times 10^{-4}\right)$ \\
Oviposition rate/female/day & $0 \cdot 40$ & $0 \cdot 37$ \\
& $(0 \cdot 16: 0 \cdot 81)$ & $(0 \cdot 16: 0 \cdot 72)$ \\
Female body weight $(\mathrm{mg})$ & $0 \cdot 016$ & 0.009 \\
& $(0 \cdot 007: 0.032)$ & $(0 \cdot 004: 0.059)$ \\
\hline
\end{tabular}

Table 3 Estimated genetic correlations between female development period $\left(t_{j}\right)$, instantaneous mortality rate $\left(\mu_{j}\right)$, daily oviposition rate $(N)$ and female body weight (bwt), for the W and W-P populations of $S$. oryzae. 95 per cent confidence intervals are in parentheses

\begin{tabular}{|c|c|c|c|c|}
\hline \multirow[b]{2}{*}{ Character } & \multirow[b]{2}{*}{ Population } & \multicolumn{3}{|l|}{ Character } \\
\hline & & $\mu_{j}$ & $N$ & bwt \\
\hline$t_{j}$ & $\begin{array}{l}\text { W } \\
\text { W-P }\end{array}$ & $\begin{array}{l}-0.14 \\
(-0.79: 0.66) \\
0.39 \\
(-0.14: 0.75)\end{array}$ & $\begin{array}{l}0.06 \\
(-0.64: 0.71) \\
0 \cdot 10 \\
(-0.44: 0.58)\end{array}$ & $\begin{array}{l}-0 \cdot 24 \\
(-0 \cdot 8: 0 \cdot 58) \\
-0 \cdot 07 \\
(-0 \cdot 76: 0 \cdot 68)\end{array}$ \\
\hline$\mu_{j}$ & $\begin{array}{l}\text { W } \\
\text { W-P }\end{array}$ & & $\begin{array}{l}0.97^{*} \\
(0 \cdot 10: 1 \cdot 84) \\
44 \\
-0 \cdot 04: 0 \cdot 75)\end{array}$ & $\begin{array}{l}0.02 \\
(-0.60: 0.62) \\
-0.05 \\
(-0.69: 0.63)\end{array}$ \\
\hline$N$ & $\begin{array}{l}\text { W } \\
\text { W-P }\end{array}$ & & & $\begin{array}{l}-0.04 \\
(-0.51: 0.45) \\
0.54 \\
(-0.04: 0.85)\end{array}$ \\
\hline
\end{tabular}

\footnotetext{
* Significantly different from zero $(P<0.05)$.
}

\section{DISCUSSION}

There was support for the existance of genetic trade-offs between the primary fitness characters in the ancestral (wheat) environment (prediction 1), with one out of a possible three genetic correlations being significantly different from zero (table 3 ). As a result of genetic trade-offs, we expected to find significant levels of additive genetic variation (prediction 2), which we did (table 2). On transfer to the new, toxic (yellow split-pea) environment we expected additive genetic variance to increase due to expression of new genes (prediction 3), and substantial increases were observed in two of the three primary characters, although only one was significant (table 2). Presumably, with the 
passing of time, natural selection would reduce $V_{a}$ for these characters to pretransfer levels. Finally, we expected the adapted genetic correlations in the $\mathrm{W}$ population to break down in the novel environment (prediction 4). Following transfer to yellow split-pea two large changes in the values of the genetic correlations were observed. Although neither change was statistically significant, both were in the predicted direction (table 3 ). Therefore, our predictions were well supported by the data and where significant effects were found they were all as predicted (five out of five).

In order to test our predictions, it was necessary to obtain statistically precise measurements. However, it is difficult to measure genetic variances and covariances precisely. As a consequence, the errors attached to estimates of genetic correlation are usually very large, offering at best only a qualitative picture. Furthermore, in order to calculate unbiased standard errors of genetic parameters it is essential for the data set to be normally distributed and well balanced. This is very hard to achieve in practice. Because of these problems some workers do not attach errors to estimates of $V_{a}$ and $r_{a}$ (e.g., Via, 1984). It is surprising that the use of non-parametric resampling procedures, such as the Jackknife (Arveson and Schmitz, 1970; Miller, 1974) and the Bootstrap (Efron, 1982; Efron and Gong, 1983), have not been used more widely. The advantages of, for example the Jackknife as used here, are that the data set does not have to be balanced and the error estimates remain robust even under conditions of non-normality. These benefits have been recognized by some life history geneticists (e.g., Via, 1984), but despite requiring only sufficient computing power to conduct the analysis (Diaconis and Efron, 1983), resampling procedures have yet to be adopted by quantitative geneticists.

Other workers have succeeded in demonstrating genetic trade-offs between fitness characters, for example Simmons et al., (1980), Rose and Charlesworth (1981a) and Luckinbill et al., (1984) using Drosophila and Soliman (1982) using Tribolium. However, more often than not, experimental studies result in $r_{a}$ values inconsistent with the trade-off hypothesis (e.g., Giesel and Zettler, 1980; Giesel et al., 1982; Stearns, 1983; Murphy et al., 1983; Bell, 1984a, b). Many of the latter studies involved the use of small or laboratory inbred populations which, as well as reducing net fitness (Mackay, 1985) can also result in spurious $r_{a}$ values between fitness characters (Rose, 1984). It is the case that siblings were mated with each other in the present study and this type of breeding regime could influence genetic trade-offs in the way described by Rose (1984). However, the populations of $S$. oryzae were highly genetically variable (Holloway, 1984), reducing the likelihood of the pairing of deleterious alleles and the sire groups performing badly (i.e., breeding values estimated from five or fewer points) were omitted from the analysis. All of the $r_{a}$ values between the primary fitness characters estimated in the $\mathrm{W}$ population had signs consistent with the existence of genetic trade-offs.

A second important reason why so often workers fail to obtain results consistent with genetic trade-offs is that experiments are carried out in environments that the animals have not previously experienced. Service and Rose (1985) pointed out the effect of environmental conditions in determining the sign and magnitude of genetic correlations. The data presented here illustrate the importance of carrying out investigations into the genetic architecture of adaptation in the environment in which the population evolved to avoid obtaining spurious genetic relationships.

Genes produce the physiology and it is largely via the physiology that genes influence fitness (Sibly and Calow, 1986). Genes with negative pleiotropic effects on two life-cycle characters control the energy partitioning process at the physiological level and the partitioning of energy between fitness characters ultimately determines fitness. For example, energy may be partitioned between production, which influences the phenotypic values of $N$ and $t_{j}$, and mechanisms offering protection against harmful xenobiotics, which affects $\mu_{j}$. The Leguminosae as a group contain a wide range of toxic secondary compounds (Harborne et al, 1971), so a population of $S$. oryzae transferred to yellow split-pea may be subjected to a range of novel selective forces. Legumes are toxic to most $S$. oryzae (Holloway, 1986a) and rather few populations of $S$. oryzae possess the ability to feed and breed on yellow split-pea (Coombs et al., 1977). However, where the ability does occur it is genetically determined (Thind and Muggleton, 1981; Holloway and Smith, 1985). There are many examples of gene based detoxifying systems in $S$. oryzae, such as resistance to DDT (Champ, 1967) and to pyrethroids (Heather, 1986). The effect of the toxins in yellow split-pea is probably to select for increased energy into survival by increasing the activity of certain detoxifying enzymes (Holloway and Mackness, 1988). The consequence of the repartitioning process might be that less energy is available for development and reproduction, hence the larval development period (egg to emer- 
gent adult) should increase and the daily oviposition rate should decrease. Table 1 shows that the expected changes had occurred in the W-P population after five generations of selection on yellow split-pea. In addition, adult female W-P insects were significantly larger than adult female W insects. It is well known that the larger individuals of an insect population are able to tolerate higher doses of synthetic insecticides (e.g., Tomato moth, Diataraxia oleracea L. (Way, 1954) and Locusts (McCuaig, 1956)). In particular, in $S$. oryzae there is a positive correlation between body size and time to knock-down in the presence of the organophosphate insecticide pirimiphos methyl and this correlation may be influenced genetically (Holloway, 1986 b). Hence an increase in body weight following transfer to a toxic environment (yellow split-pea) was to be expected.

Since Williams (1966) proposed the theory of serial pleiotropic gene action to account for senescence, numerous theoretical papers have appeared in the literature which have strengthened our understanding of the role of negative pleiotropy and trade-offs in the evolution of life-cycles. Rather fewer experimental tests of the theory have been conducted and, as the review by Bell and Koufopanou (1986) shows, the results of many of these studies are apparently at odds with the genetic trade-off hypothesis. One possible reason for these discrepancies is that the effects of environmental change on genetic architecture have been insufficiently appreciated.

Acknowledgements The work was funded by NERC grant number GR3/6424. We are very grateful to Dr R. H. Smith, Professor R. Curnow and Dr P. Avery for many hours of advice and discussion concerning the statistical analysis and to Mrs H. R. Barsby for technical assistance. The insects were originally provided by Dr P. Dobie of the Overseas Development of Natural Resources Institute, Slough, U.K.

\section{REFERENCES}

ARVESEN, J. M. AND SCHMITZ, T. H. 1970. Robust procedures for variance components problems using the jackknife. Biometrica, 26, 677-686.

BECKER, W. A. 1967. Manual of Quantitative Genetics (2nd edn). Washington State University, Washington.

BELL, G. 1984a. Measuring the cost of reproduction. I. The correlation structure of the life table of a plankton rotifer. Evolution, 38, 300-313.

BELL, G. $1984 b$. Measuring the cost of reproduction. II. The correlation structure of the life tables of five freshwater invertebrates. Evolution, 38, 314-326.

BELL, G. AND KOUFOPANOU, V. 1986. The Cost of Reproduction. In Dawkins, R. and Ridley, M. (eds) Oxford Surveys in Evolutionary Biology, vol. 3. Oxford University Press, New York. pp. 83-131.
CHAMP, B. R. 1967. The inheritance of DDT resistance in Sitophilus oryzae (L.) (Coleoptera, Curculionidae). J. stored Prod. Res., 4, 175-178.

CHAMP, B. R. AND DYTE, C. E. 1976. Report of the FAO global survey of pesticide susceptibility of stored grain pests. FAO plant production and protection series no. 5. Rome.

COOMBS, C. W., BILlingS, C. J. AND PORTER, J. E. 1977. The effect of yellow split-peas (Pisum sativum L.) and other pulses on the productivity of certain strains of Sitophilus oryzae (L.) (Col. Curculionidae) and the ability of other strains to breed thereon. J. stored Prod. Res., 13, 53-58.

DIACONIS, P AND EFRON, B. 1983. Computer intensive methods in statistics. Sc. Amer., 248, No 5, 96-108.

EFRON, B. 1982. The jackknife, the bootstrap and other resampling plans. Society for Industrial and Applied Mathematics., $93 \mathrm{p}$.

EFRON, B. AND GONG, G. 1983. A leasurely look at the bootstrap, the jackknife and cross-validation. Amer. Statist., 37, 36-48.

EVANS, D. E. 1982. The influence of temperature and grain moisture content on the intrinsic rate of increase of Sitophilus oryzae (L.). J. stored Prod. Res., 18, 55-66.

FALCONER, D. S. 1981. Introduction to Quantitative Genetics (2nd edn). Longman, London.

Giesel, J. T., MURPHY, P. A. AND MANLOVE, M. N. 1982. The influence of temperature on genetic interrelationships of life-history traits in a population of Drosophila melanogaster: what tangled data sets we weave. Am. Nat, $119,464-479$.

GIESEL, J. T. AND ZETTLER, E. E. 1980. Genetic correlations of life-historical parameters and certain fitness indices in Drosophila melanogaster: $\mathrm{r}_{\mathrm{m}}, \mathrm{r}_{\mathrm{s}}$ and diet breadth. Oecologia, 47, 299-302.

Goodenough, U. 1978. Genetics (2nd edn). Holt, Rinehart and Winston, London.

HARBORNE, J. B., BOULTER, D. AND TURNER, B. L. 1971. Chemotaxonomy of the Leguminosae. Academic Press Inc., London. 612pp.

HEATHER, N. W. 1986. Sex-linked resistance to pyrethroids in Sitophilus oryzae (L.) (Coleoptera: Curculionidae). J. stored Prod. Res., 22, 15-20.

holloway, G. J. 1984. Genetic Differentiation and Life History Variation in the Rice Weevil, Sitophilus oryzae. Ph.D. Thesis, University of Reading. pp218.

HOLLOWAY, G. J. 1985. The effect of increased grain moisture content on some life history characters of Sitophilus oryzae after staining egg plugs with acid fuchsin. J. stored Prod. Res., 21, 165-169.

HOLLOWAY, G. J. 1986a. The potency and effect of phytotoxins within yellow split-pea (Pisum sativum) and adzuki bean (Vigna angularis) on survival and reproductive potential of Sitophilus oryzae. (Coleoptera: Curculionidae). Bull. ent. Res., 76, 287-295.

HOLlOWAY, G. J. $1986 \mathrm{~b}$. A theoretical examination of the classical theory of inheritance of insecticide resistance and the genetics of time to knockdown and dry body weight in Sitophilus oryzae (L.) (Coleoptera: Curculionidae). Bull. ent. Res., 76, 661-770.

HOLlOWAY, G. J. AND MACKNESS, M. T. 1989. The evolutionary adaptation of enzyme systems in Sitophilus oryzae fed on toxic legumes. Ent. exp. appl., 48, 165-172.

HOLlOWAY, G. J. AND SMITH, R. H. 1985. Inheritance of the ability of Sitophilus oryzae (L.) (Coleoptera: Curculionidae) to feed and breed on yellow split-pea (Pisum sativum), Bull. ent. Res., 75, 367-375.

KRZANOWSKI, W. J. 1988. Principles of Multivariate Analysis. A Users Perspective, Clarenden Press, Oxford. 
LUCKINBILL, L. S., ARKING, R., CLARE, M. J., CIROCCO, W. C. AND BUCK, S. A. 1984. Selection for delayed senescence in Drosophila melanogaster. Evolution, 38, 996-1003.

MACKAY, T. F. C. 1985. A quantitative analysis of fitness and its components in Drosophila melanogaster. Genet. Res., $47,59-70$.

MACCUAIG, R. D. 1956. Determination of resistance of locusts to DNC in relation to their weight, age and sex. Ann. appl. Biol., 44, 634-642.

MILleR, R. G. 1974. The jackknife- a review. Biometrika, 61, $1-15$.

MØLLER, H., SMITH, R. H. AND SIBLY, R. M. 1989. Evolutionary demography of a bruchid beetle. I. Quantitative genetical analysis of the female life history. Funct. Ecol., 3673-3681.

MURPHY, P. A., GIESEL, J. T. AND MANLOVE, M. N. 1983. Temperature effects on life history variation in Drosophila simulans. Evolution, 37, 1181-1192.

POVEY, S. R., SIBLY, R. M. AND HOLLOWAY, G. J. (in preparation) Evolution of insect life cycles in toxin-stressed environments: investigation of trade-offs using reciprocal transplant experiments.

RICHARDS, O. W. 1947. Observations on grain weevils Calandra (Col. Curculionidae). General Biology and oviposition. Proc. Zool. Soc. Lond., 117, 1-43.

ROSE, M. R. 1982. Antagonistic pleiotropy, dominance and genetic variation. Heredity, 48, 63-78.

ROSE, M. R. 1984. Genetic covariance in Drosophila life history: untangling the data. Am. Nat., 123, 565-569.

ROSE, M. R. AND CHARLESWORTH, B. $1981 a$. Genetics of life history in Drosophila melanogaster. I. Sib analysis of adult females. Genetics, 97, 173-186.

ROSE, M. R. AND CHARLESWORTH, B. $1981 \mathrm{~b}$. Genetics of life history in Drosophila melanogaster. II. Exploratory selection experiments. Genetics, 97, 187-196.

SEARLE, S. R. 1971. Linear Models. John Wiley and Sons, New York.

SERVICE, P. M. AND ROSE, M. R. 1985. Genetic covariation among life-history components: the effect of novel environments. Evolution, 39, 943-945.

ShAZAli, M. E. H. 1982. The Biology and Population Ecology of Four Insect Pests of Stored Sorghum with Particular Reference to Competition and Succession. Ph.D. Thesis, University of Reading.
SIBLY, R. M. 1989. What evolution maximizes. Funct. Ecol., 3, 129-135.

SIBLY, R. M. AND CALOW, P. 1986. Physiological Ecology of Animals: an Evolutionary Approach. Blackwell, Oxford. pp179.

SIMMONS, M. J., PRESTON, C. R. AND ENGELS, W. R. 1980. Pleiotropic effects on fitness of mutations affecting viability in Drosophila melanogaster. Genetics, 94, 467-475.

SINGH, S. R. AND SODERSTROM, E. L. 1963. Sexual selection of the rice weevil Sitophilus oryzae (L.) as indicated by sperm transfer and viable eggs. J. Kans. ent. Soc., 36, 32-34.

SOKAL, R. R. AND ROHLF, F. J. 1981. Biometry. W. H. Freeman and Co, San Francisco.

SOLIMAN, M. H. 1982. Directional and stabilizing selection for developmental time and correlated response in reproductive fitness in Tribolium castaneum. Theoret. Appl. Gen., 63, 111-116.

STEARNS, S. C. 1983. The genetic basis of differences in life history traits among six populations of mosquito fish ( $\mathrm{Gam}$ busia affinis) that shared common ancestors in 1905. Evoiution, 37, 618-627.

STRICKBERGER, M. W. 1968. Genetics. Collier Macmillan Ltd, London.

THIND, B. B. AND MUGGLETON, J. 1981. Inheritance of the ability of strains of Sitophilus oryzae (L.) (Coleoptera: Curculionidae) to breed on split-pea (Pisum sativum). Bull. ent Res., 71, 419-424.

VIA, S. 1984. The quantitative genetics of polyphagy in an insect herbivore. I. Genotype-environment interaction in larval performance on different host plant species. Evolution, 38, 881-895.

WAY, M. J. 1954. The effect of body weight on the resistance to insecticide of the last instar larva of Diataraxia oleracea L., the tomato moth. Ann. appl. Biol., 47, 77-87.

WILliAMS, G. C. 1966. Natural selection, the costs of reproduction and a refinement of Lack's principle. Amer. Nat., 100, 687-690. 